\title{
Rational Prescription and Cost-Effective Medication: Challenges and Opportunities in Pakistan
}

\author{
Fahmida Aslam, MS, PharmD ${ }^{1}$; Faiz Ullah Khan, MPhil, PharmD ${ }^{2,3,4,5}$; Yang Yue, PhD
}

${ }^{1}$ International Food and Drug Policy Law and Research Centre, School of Business Administration; Shenyang Pharmaceutical University, China; '2Department of Pharmacy Administration and Clinical Pharmacy, School of Pharmacy Xi'an Jiaotong University, Xi'an, China; ${ }^{3}$ Center for Drug Safety and Policy Research, Xi'an Jiaotong University, Xi'an, China; ${ }^{4}$ The Global Health Institute, Xi'an Jiaotong University, Xi'an, China; ${ }^{5}$ Shaanxi Centre for Health Reform and Development Research, Xi'an, China

\begin{abstract}
Pakistan is one of the countries with the highest number of medications filled per prescription due to overly prescribed antibiotics and injectable drugs. This is due to a lack of ethical practices in prescribing because doctors are significantly influenced by lucrative financial incentives of pharmaceutical companies rather than clinical findings. This immoral activity has become significantly amplified over the past few years and continues to be a challenge in Pakistan. Currently, there is no code of ethics for marketing and promotional activities of pharmaceutical companies. This year, authorities have step up and are in the process of creating policies to regulate companies and practitioners. Implementation of these new policies needs vigilance from health officials, strong professional commitment and institutional collaboration. If executed correctly, these polices should create an environment of professionalism within the healthcare sector.
\end{abstract}

Keywords: Rational prescription, Brands names, Generic names, cost-effective medication, Pakistan

\section{Introduction}

According to the World Health Organization (WHO), Pakistan is the fifth most populous developing country in the Eastern Mediterranean Region. ${ }^{1}$ Pakistan has a significant deficiency in the health budget and lacks efficiency with regards to regulation of the health sector. ${ }^{2}$ A sizable proportion of the health care system is made up of private firms. ${ }^{3}$ According to the Human Development Index (HDI), Pakistan is ranked 145 amongst 189 countries with regards to life expectancy and has a lower life expectancy than Indonesia, Malaysia, and Sri Lanka. ${ }^{1}$ In Pakistan, $77 \%$ of healthcare expenditures revolve around medication purchase. ${ }^{4}$ Inappropriate medication use is a significant concern with antibiotics, anti-cancer, hormones, narcotics; and psychotropic being misused the most often. ${ }^{5}$

In Pakistan, the average number of drugs per prescription was 4.4, which is highest in the world. ${ }^{6}$ Overprescribing of antibiotics was documented, however about $70 \%$ patients were prescribed antibiotics ${ }^{5,6}$. Large number of prescriptions were found inappropriate in Pakistan specifically antimicrobials about $60 \%$ patients prescribed antimicrobials and less $20 \%$ patients were prescribed properly ${ }^{7}$ Large number of qualified medical practitioners frequently prescribe inappropriately even for prevalent diseases like treatment for psychiatric and pediatrics diseases did not relate to diagnosis in $25 \%$ cases and doses of medicines were incorrect in 31\% prescriptions. More than $76.5 \%$ medicines of the unknown composition which known as mixtures are dispensed by practitioners. These

Corresponding author: Fahmida Aslam, MS, PharmD

Shenyang Pharmaceutical University, China

Email: phfahmida@yahoo.com

Phone: 008617800224476 mixtures made in their own medicine dispensing area which is not open to monitoring. ${ }^{5}$ Globally, Pakistan has the highest rate of injectable medication use, with more than 60 percent of patients receiving prescriptions-it is estimated that $90 \%$ of these prescriptions were unneccessary. ${ }^{4}$ In addition to the overprescribing of unnecessary medications, many prescribers also add new, expensive, first- line therapies along with concomitant use of over-the-counter products such as multivitamins and minerals which leads to poly-pharmacy complications. $^{8}$ To make matters worse, more than $50 \%$ of medications are prescribed for the brand name which further impacts the economic burden placed on patients. ${ }^{6}$

In developing countries like Pakistan, the largest contributing factors to irrational use of medications are unethical practices from prescribers, pharmaceutical companies, and regulatory authorities. ${ }^{9}$ Prescription analysis is essential in identifying the root cause of poor prescribing habits and creating long-term solutions. The WHO has suggested five basic indicators that can help flag irrational prescribing habits. These indicators are: the number of medications prescribed, trends associated with overprescribed medications such as antibiotics and injections, the percentage of generic vs. brand name prescriptions, dispensing and consulting time and the number of drugs from the National Essential Medicine List (NEML). ${ }^{10}$ Rational prescribing and quality use of medications remains a neglected domain within medical practice in Pakistan. ${ }^{14}$ The International Network for the Rational Use of Drugs (INRUD) and WHO Action Program on Essential Drugs (WHO/DAP) collaborate and support many developing countries like Zimbabwe and Indonesia. They provide international indicators, methodologies and standard to deliver benchmark. Since the assistance of these programs, the ethical prescribing of medications has significantly improved in these countries. ${ }^{15,9}$ 


\section{Medicine marketing and irrational prescriptions}

Globally, the annual corruption expenditure is estimated to be \$4.4 trillion dollars with the majority of these unethical practices occurring in the healthcare sector. ${ }^{16}$ Bribery impacts not only developing countries such as India and Pakistan, but also established markets such as China, United Kingdom and The United States. ${ }^{17}$ The goal would be to target deceitful practices in the pharmaceutical sector and address issues such as bribery, embezzlement, falsification of safety information, forgery of efficacy, preferential contracts with companies and burglary within the supply chain. ${ }^{16}$ The Department of Justice in the US has already fined pharmaceutical companies billions of dollars for unethical marketing. The pharmaceutical companies in United Kingdom has lost between $10 \%$ and $25 \%$ due to health care corruption and even China has experienced significant problems due to the same unethical practices. ${ }^{17}$

Currently, Pakistan has more than 600 medication manufacturing units and 88,000 registered medicinal products which is the highest number of drug products among underdeveloped countries. ${ }^{1,5}$ Due to the large number of pharmaceutical companies, the competition is fierce and many businesses commence unethical promotional tools and activities to attain a market share. ${ }^{15}$ The associations between physicians and companies has become more business oriented $^{19}$ and this significantly influences the prescribing behavior. Prescribers are swayed to dispense certain products by receiving gifts that include: books, cars, clinical appliances, membership to associations, drug samples, fancy dinners, home appliances, seminars, and funding for conferences. ${ }^{17,20}$ To gain maximum financial benefit from pharmaceutical companies, doctors prescribe the maximum number of drug products, which ${ }^{22}$ increases the cost of medical care for patients. More than $60 \%$ of pharmaceutical companies confess that contemporary marketing activities are unethical and $51 \%$ admit guilt for these practices. ${ }^{23}$ Strong healthcare legislation must be introduced to control and reverse these immoral practices. $^{24}$

\section{Prescribing medications by brand names}

In Pakistan, most prescribers write for brand name prescriptions ${ }^{8,16}$ which has led to a substantial increase in costs for patients. ${ }^{26,27}$ It is important to enact appropriate legislations and policies to prohibit these practices.

\section{Frame of policies and efforts in Pakistan}

In 2004, WHO strategized a program entitled "Good Governance for Medicine" (GGM), its initiative to concretely address the need for transparency and unethical marketing of medication in various parts of world. Moreover, to stimulate individual and influential reliability in the pharmaceutical sector. This program operates in more than 26 countries globally and includes Malaysia, People's Democratic Republic Lao, Philippines and Thailand. ${ }^{28}$ Guidelines such as transparency in revision of pharmaceutical laws and regulations to meet international recognized standard, transparent medicine procurement which leads towards fairer competition gained from this program can be helpful for prospective efforts and strategies in Pakistan. ${ }^{15}$ GGM recommends that policy changes alone is not adequate to overcome the corruption, there must be a strong level of commitment coupled with the collaboration of anti-corruption agencies to bring about change. ${ }^{28}$

As of now, certain provincial authorities have made a small number of policies to ensure prescribers are following ethical prescribing habits and ensuring generic forms of the medication are being dispensed; however, this number is far too few to have a significant impact on the greater population. ${ }^{31,32,33}$

In the past, the Pakistan Medical \& Dental Council (PMDC) established a code of ethics for practitioners (1962) and its final revised form was introduced in 2001. These codes of ethics drew attention to the importance of rational drug use and clearly notates that practitioners should not accept any financial kickbacks. ${ }^{9}$ However, this sector seems to be ignored by health authorities as well as policymakers.

In September 2016, the Drug Regulatory Authority of Pakistan (DRAP) stepped forward to draft a code of conduct for pharmaceutical companies in an attempt to monitor drug promotion activities. A committee of experts has been appointed to outline the policy and will consist of healthcare providers, governmental officials, and representatives of the consumer councils. The ultimate goal will be to ensure ethical prescribing habits by monitoring the ties between companies and healthcare practitioners. ${ }^{29,30}$ Authorities are planning to pilot this project in government hospital immediately and expand to ${ }^{33}$ all the provincial areas.

\section{Conclusion}

Hopefully, the creation of new policies will help to overcome the unethical marketing of pharmaceutical companies and will change the current prescribing behavior of healthcare providers. If the policies are enforced appropriately, we should see prescribers writing prescriptions for clinical efficacy with patient affordability in mind. We should see an increase in the prescribing of drugs by their generic name which will help to safeguard the rights of patients and their interest. Additionally, promotional budgets for medication marketing will be controlled and should help to minimize the medication prices and increase the availability of cost-effective medicines. In short, these policies will ultimately decrease the economic burden on patients and increase the accessibility to quality medicine. Furthermore, it should also increase the professionalism in practitioners and pharmaceutical companies. In short, these policies should be potential landmarks in the healthcare system of Pakistan. It is important to note that implementation of these polices will take time, but proper execution will ensure success. Through the use of vigilance, dedication, professional commitment and institutional collaboration, we can bring the necessary change to improve the healthcare landscape in Pakistan. 
Conflicts of interest/Competing interests: The authors declare that there is no conflict of interest.

\section{References}

1. Country Cooperation Strategy for WHO and Pakistan 20112017. 2017:1-57.

2. Ahmed J, Shaikh BT. An all time low budget for healthcare in Pakistan. J Coll Physicians Surg Pakistan. 2008;18(6):388391.

3. WHO. PRIMARY CARE SYSTEMS PROFILES \&amp; PERFORMANCE (PRIMASYS). Hum Resour Health. 2011;9. doi:10.1002/hpm.2299

4. Babar ZUD, Jamshed S. Social pharmacy strengthening clinical pharmacy: Why pharmaceutical policy research is needed in Pakistan? Pharm World Sci. 2008;30(5):617-619. doi:10.1007/s11096-008-9246-z

5.1020365@www.dawn.com. https://www.dawn.com/news/1020365.

6. WHO. the World Medicines. 2004. http://apps.who.int/medicinedocs/es/d/Js6160e/.

7. Sarwar MR, Saqib A, Iftikhar S, Sadiq T. Antimicrobial use by WHO methodology at primary health care centers: a cross sectional study in Punjab, Pakistan. BMC Infect Dis. 2018;18(1):492. doi:10.1186/s12879-018-3407-z

8. Das N, Khan AN, Badini ZA, Baloch H, Parkash J. Prescribing Practices of Consultants at Karachi, Pakistan. J Pak Med Assoc. 2001;51(2):74-77.

9. Hussain A, Izham M, Ibrahim M, Baber Z. Inventory Article Using the potentials of community pharmacies to promote rational drug use in Pakistan : An opportunity exists or lost ? J Pak Med Assoc. 1990;62(11):1217-1222. doi:10.1210/jc.2003-031028

10. Arshad S, Mahmood S, Rasool S, Hayat S, Zafar S, Zehra T. Rational Drug use in Pakistan: A systematic review. J Pharm Pract Community Med. 2016;2(24):116-122. doi:10.5530/jppcm.2016.4.3

11. Aslam A, Khatoon S, Mehdi M, Mumtaz S, Murtaza B. Evaluation of Rational Drug Use at Teaching Hospitals in Punjab, Pakistan. J Pharm Pract Community Med. 2016;2(2):54-57. doi:10.5530.jppcm.2016.2.6

12. Kazi $Y$, Nadeem M, Iqbal J. RATIONAL USE OF DRUGS ACCORDING TO WHO GUIDELINES FOR HEALTH CARE PROFESSIONAL IN DIFFERENT HOSPITALS OF KARACHI , PAKISTAN. 2012;2(4).

13. Atif M, Sarwar MR, Azeem M, et al. Assessment of WHO/INRUD core drug use indicators in two tertiary care hospitals of Bahawalpur, Punjab, Pakistan. J Pharm Policy Pract. 2016;9(1):27. doi:10.1186/s40545-016-0076-4

14. Zaidi S, Nishtar NA. Rational prescription \& use: A snapshot of the evidence from Pakistan and emerging concerns. Int $J$ Pharm Pharm Sci. 2013;5(SUPPL.1):131-135.

15. Laing R. Ten recommendations to improve use of medicines in developing countries. Health Policy Plan. 2001;16(1):1320. doi:10.1093/heapol/16.1.13

16. U.A. R, T. K, M. I, M. A, U.M. I. Prescription patterns of general practitioners in peshawar, Pakistan. Pakistan J Med Sci. 2014;30(3):462-465. doi:10.12669/pjms.303.4931

17. Shamim-ul-haq S, Ahmed RR, Ahmad N, Parmar V. Factors Influencing Prescription Behavior of Physicians. 2014;3(722):30-35.
18. Sarpatwari A, Avorn J, AS K. An incomplete prescription: President trump's plan to address high drug prices. JAMA. 2018;319(23):2373-2374. http://dx.doi.org/10.1001/jama.2018.7424.

19. Ahmed RR. Pharmaceutical Industry in Pakistan : Unethical Pharmaceutical. Pharm Ind Pakistan Unethical Pharm Mark Pract. 2008;4(2).

http://pafkiet.edu.pk/marketforces/index.php/marketforce s/article/view/184.

20. Srinivasan S. The Drug Industry and Doctors : An Unholy Alliance.

21. Yousafzai AW. Corruption in Medical Practice: Where Do We Stand? J Ayub Med Coll Abbottabad JAMC. 2015;27(3):515-516.

22. Asif I, Amin S. The Impact of Doctor - Pharma Relationships on Prescribing Practice. 2012:174-180.

23. Ahmad M, Akhtar N, Awan MH a, Murtaza G. Ethical Evaluation of Pharmaceutical Marketing in Pakistan. Acta Bioeth. 2011;17(2):215-224. doi:10.4067/S1726569X2011000200008

24. Ahmed RR, Saeed A. Pharmaceutical drug promotion in Pakistan: Issues in ethical \& non-ethical practices. Interdiscip J Contemp Res Bus. 2012;4(4):149-164. doi:10.5829/idosi.mejsr.2014.20.11.82414

25. Nishtar S, Bhutta ZA, Jafar TH, et al. Health reform in Pakistan: A call to action. Lancet. 2013;381(9885):22912297. doi:10.1016/S0140-6736(13)60813-2

26. Rao S. Prescription Writing- Generic or Brand. Indian J Psychatry. 2017;59:3-5. doi:10.4103/psychiatry.IndianJPsychiatry 222_17

27. Flegel K. The adverse effects of brand-name drug prescribing. Cmaj. 2012;184(5):616. doi:10.1503/cmaj.112160

28. Baghdadi-Sabeti G and Serhan F. WHO Good Governance for Medicines programme: an innovative approach to prevent corruption in the pharmaceutical sector. 2010. http://www.who.int/healthsystems/topics/financing/health report/25GGM.pdf.

29. 1286115 (Accessed at 12 Feb 2017) @ www.dawn.com. https://www.dawn.com/news/1286115 (Accessed at 12 Feb 2017).

30. 151589-DRAP-preparing-code-of-ethics-to-curb-illegalpractices (Accessed at 12 Feb 2017) @ www.thenews.com.pk. https://www.thenews.com.pk/print/151589-DRAPpreparing-code-of-ethics-to-curb-illegal-practices (Accessed at 12 Feb 2017).

31. 2dbdc63dca02ea244225a7e18a9935a4078fe92d @ tribune.com.pk. https://tribune.com.pk/story/1672829/1back-basics-prescribe-drugs-generic-rather-brand-name/.

32. 6193353f0a27ab118843b9967aefb370cd49e2e4 @ tribune.com.pk. https://tribune.com.pk/story/1313519/branded-drugs-k-pmay-act-gps/.

33. health-department-plans-to-introduce-genericprescriptions-in-hospitals (Accessed at 7 April 2018) @ www.dawn.com.

https://www.dawn.com/news/1399794/healthdepartment-plans-to-introduce-generic-prescriptions-inhospitals (Accessed at 7 April 2018). 